\title{
ISLAM, TRANSNACIONALNA OBLEKA IN IDENTITETA: MIGRACIJE PODOB, TRANSFORMACIJE POMENOV
}

\author{
Mateja KROFL'
}

COBISS 1.02

\section{IZVLEČEK}

Islam, transnacionalna obleka in identiteta: Migracije podob, transformacije pomenov

Migracije in globalizacija danes ključno vplivajo na redefiniranje muslimanske obleke v sodobnosti ter oblikovanje kulturne identitete žensk islamske veroizpovedi v urbanem okolju. Raznolike sodobne oblačilne sloge muslimank je danes treba razumeti v kontekstu porasta neoliberalne ekonomije v muslimanskih državah ter ponovnega oživljanja muslimanskih identitet po celem svetu. Namen članka je predstaviti transnacionalni pomen tančice (oblike naglavnega oziroma telesnega pokrivala) ter ponuditi vpogled v nove muslimanske oblačilne prakse, ki se tako simbolno kot materialno napajajo tako v »vzhodni« kot »zahodni« kulturi. Temeljita analiza tudi pokaže, da večina muslimanskih žensk nošenje tančice danes dojema kot pomemben odraz pripadnosti ter potrditev kulturne identitete. Nova transnacionalna muslimanska moda je postala večplasten koncept, ki, globoko integriran v politične, družbene, osebne in navsezadnje vizualne interpretacije, odpira nove perspektive v percepciji identitete "modernih « muslimank ter tako pomembno priča o kulturnem pomenu migracij.

KLJUČNE BESEDE: islam, transnacionalna obleka, identiteta, migracije, globalizacija

\begin{abstract}
Islam, Transnational Dress and Identity: Migration of Images, Transformation of Meanings

Contemporary Islamic dress as well as cultural identity of Islamic women in urban environment are today widely influenced and re-defined by migrations and globalization. Diverse contemporary clothing styles of Muslim women today must be understood in the context of rise of neoliberal economics in Muslim countries and the resurgence of Muslim identities worldwide. The purpose of this article is to present the transnational meaning of the veil (a form of headgear or body covering) and offer an insight into the new Muslim dressing practices which are symbolically as well as materially shaped by both 'Eastern' and 'Western' cultures. A thorough analysis also shows that in general, for the majority of Muslim women, the wearing of the veil today is perceived as an important expression of belonging and affirmation of the cultural identity. As a multi-layered concept, deeply integrated into political, social, personal and, nevertheless, visual interpretations, this new transnational Muslim fashion is thus opening up new perspectives in the perception of the identity of 'modern' Muslim women and thus revealing an important testimony to the cultural significance of migrations.
\end{abstract}

KEY WORDS: Islam, transnational dress, identity, migrations, globalization

Univ. dipl. ing. oblikovanja tekstilij in oblačil, študentka podiplomskega doktorskega študija, smer Filozofija in teorija vizualne kulture, Fakulteta za humanistične študije, Titov trg 5 , SI-6000 Koper; melussine@yahoo.com 


\section{UVOD}

Migracije, kot jih poznamo v zadnjih dveh desetletjih, so tesno povezane z globalizacijo; mednarodne korporacije, kibernetska tehnologija in elektronski množični mediji danes prepletajo kulture po celotnem kontinentu. Njihov vpliv se odraža tudi v globalni percepciji oblačil glede na to, kako so ta proizvedena, marketirana, prodajana, kupljena, oblečena in odvržena. T. i. "globalni stil« (Kaiser 1999), ki se je pojavil kot rezultat globalizacije v produkciji mode, odslikava globalne trende, izražene v modnih podobah $\mathrm{v}$ revijah, glasbeni industriji, na filmu, internetu in televiziji. Džins, T-shirt, teniske in bejzbolske kape se danes pojavljajo vse od ulic New Yorka do afriških vasi. To fizično sposojanje stila in tekstilnih elementov, ki poteka med Zahodom, ${ }^{1}$ Azijo in Afriko, je "globalni paradoks - pojav, ki ga opredeljujeta tako homogenizacija med različnimi lokacijami kot tudi raznolikost znotraj posameznih geografskih lokacij« (prav tam).

Globalizacija in migracije ne oblikujejo le svetovne ekonomije in globalne kulture, ampak definirajo tudi vsakdanje življenje posameznikov. Kulturni kontekst migracij, od kulinarike, športa, umetnosti, medijev do mode, v novi kulturno pluralistični družbi ustvarja nove hibridne oblike in kulturne difuzije. „Človeških družb in kultur ne moremo prav razumeti, če si jih ne zamišljamo v medsebojnih razmerjih in odvisnostih v prostoru in času (Wolf 1998: 9). Prepletenost sodobnega sveta lahko opišemo kot »interaktivni sistem« (Appadurai 1996: 27), ki ga zaznamujeta »translokalnost» ter »disjunkcija» ali mimobežnost globalnih kulturnih tokov, ki zajemajo ljudi, stvari, podobe in predstave, diskurze, kapital, ideologije, tehnologije, medije itd. Za preučevanje razsrediščenega svetovnega sistema Appadurai predlaga rabo dinamičnih prostorsko-kulturnih kategorij ali 'krajin' (ang. scapes), ki opisujejo globalne kulturno-ekonomske mimobežne in razhajajoče tokove (prav tam). Čeprav so krajine med seboj neločljivo povezane, jih razdeli na etnične, tehnične, finančne, medijske in idejne. Posamezniki, ki se selijo, s seboj prenašajo različne kulturne predstave, vzorce, kapital, vplive, znanja itd. (Repič 2009). V migracijskih kontekstih kultura, ali natančneje kulturne razlike, prevzamejo vlogo označevalcev kolektivne identitete, s tem pa postanejo tudi mehanizem za legitimacijo socialnega vključevanja in izključevanja (prav tam). »Kultura je dimenzija človeškega diskurza, ki uporablja razlike, da oblikuje raznolika pojmovanja človeške identitete« (prav tam: 13).

Med najrazvidnejšimi oblikami kulturne migracije je tudi kultura oblačenja. V pričujočem prispevku se osredotočam na sodobno muslimansko "tančico,${ }^{2}$ ki je med najbolj spornimi zadevami emigrantskih žensk $\mathrm{v}$ deželah, $\mathrm{v}$ katere so se muslimani priselili. Čeprav Zahod tančico na splošno razume kot statičen in nespremenjen simbol, že stoletja povezan predvsem s segregacijo žensk, poznavanje islamske kulture odstira nove interpretacije muslimanske obleke ter ponuja nove vpoglede v raznolikost njenih posameznih funkcij in družbenih pomenov (El Guindi 1999; Haddad 2002; Harcet 2007; Hoodfar 1997;

1 Tukaj ne mislim geografske, pač pa ideološko-politično delitev na razviti »Zahod « in nerazviti »Vhhod«. Gre za temeljno razlikovanje v politični in ekonomski moči med kapitalisti in delavci, kot ga opredeli antropolog Eric R. Wolf v delu Evropa in ljudstva brez zgodovine (1998). S pojmom »Zahod« opredeljujem krščanski del sveta, kamor spadajo Evropa, ZDA in Avstralija (tudi Japonska) in ki je v nasprotju z nekrščanskim, torej muslimanskim »Vzhodom«.

2 Izraz "tančica $\mathrm{v}$ prispevku uporabljam za vse oblike naglavnega in telesnega pokrivanja. Posamezni tipi pokrival se razlikujejo glede na različne kulture in so v nadaljevanju pojasnjeni $\mathrm{v}$ poglavju Tančica in islam. 
Hume 2013; Kaiser 2012; Kalčič 2007; Tarlo, Moors 2007; Tarlo 2010). Sodobna muslimanska moda ne le, da izziva kulturne, zgodovinske in patriarhalne principe islama, pač pa preverja kulturno in osebno identiteto »moderne« muslimanske ženske.

Glavne dileme, ki se danes pojavljajo v zvezi z oblačilno kulturo žensk islamske veroizpovedi, so nedvomno kompleksna tematika. Ta ne deli mnenj zgolj na Zahodu, ki v luči konservativnega islama pokrivanje prepogosto razume kot zatiranje žensk, temveč tudi $\mathrm{v}$ sami islamski družbi. Medtem ko nekatere ženske islamske veroizpovedi verjamejo, da z nošenjem pokrivala izražajo spoštovanje in odgovornost, ki ju imajo do svoje veroizpovedi, druge zakrivanje razumejo kot simbol upora proti moderniziranemu Zahodu. Namen prispevka ni razprava o islamu, ki bi obravnavala orientalistične ${ }^{3}$ stereotipe o religiji, pač pa prikaz »transnacionalne ${ }^{4}{ }^{4}$ na novo interpretirane muslimanske obleke v sodobnosti ter dilem v zvezi z nošenjem tančice kot simbola islama. Zanima me, kako migracijski in globalizacijski procesi vplivajo na oblikovanje sodobne muslimanske obleke in kulturne identitete muslimank. Sprašujem se o vizualnih predstavitvah sodobnih islamskih oblačilnih praks in pomenu ženskega naglavnega oziroma telesnega pokrivala v odnosu do vloge in položaja žensk islamske veroizpovedi v urbanem okolju. Predvidevam, da migracije in globalizacija $\mathrm{v}$ percepcijo identitete sodobne muslimanke $\mathrm{z}$ redefiniranjem tradicionalne muslimanske noše v mednarodni prostor vnašajo alternativne perspektive.

$\mathrm{V}$ prispevku na raziskovalna vprašanja odgovarjam s pomočjo metod kvalitativnega raziskovanja v socialni antropologiji. Uporabljam deskriptivno oziroma opisno analizo, ki je najustreznejša glede na razpoložljive vire in samo temo naloge. $Z$ diskurzivno metodo se osredotočam tako na primarne kot tudi sekundarne vire v strokovni literaturi, člankih in na spletnih straneh. Avtorica pričujočega članka sem modna oblikovalka in trenutno živim in delam v Indoneziji (državi z največjim številom prebivalstva muslimanske vere) in pri svojem preučevanju uporabljam metode opazovanje z udeležbo, introspekcije ter avtobiografsko metodo oziroma metodo življenjske zgodbe.

3 »Orientalizem« je termin, ki ga je leta 1978 v svojem kontroverznem kulturološkem delu predstavil Edward Said, začetnik postkolonialnih študij. Orientalizem je po njegovem način mišljenja, ki temelji na ontološki in epistemološki distinkciji med Orientom in Okcidentom; idej, kultur in zgodovin ni mogoče resno preučevati oziroma razumeti, ne da bi preučevali tudi njihovo moč. Nevtralna vednost ne obstaja; po Saidovem prepričanju je vsak znanstveni diskurz ne le ideološki, ampak tudi podrejen, posredno ali neposredno, centrom moči. Orient je zato konstrukt Okcidenta, saj ga ta povezuje z romantiko, eksotičnimi bitji, nepozabnimi spomini in erotičnimi doživetji (Said 1996: 15).

4 »Transnacionalizem« je povezan s konceptom multikulturalizma in vključuje ideje o mnogoterih - fluidnih - hibridnih identitetah, ki odslikavajo pripadnost mešanim skupnostim, krajem in tradicijam zunaj matične države. Predstavlja različne načine čezmejnih povezav in skupine ljudi, ki segajo preko enega samega nacionalnega, etničnega in kulturnega prostora. Transnacionalizem se lahko kaže v obliki kulturne reprodukcije, političnega udejstvovanja ter rekonstrukcije prostorskih dimenzij in lokacij. Identitete, ki se oblikujejo pod vplivom različnih nacionalnih in kulturnih imaginarijev, vključujejo tako elemente globalnega kot partikularnega (Vertovec 2001). 


\section{ZGODOVINA POKRIVANJA ŽENSK}

Pokrivanje ne le žensk, pač pa tudi moških ter svetih predmetov in prostorov je skupno številnim kulturam in religijam. Čeprav je pojem tančice oziroma pokrivanja ženskega telesa danes kontroverzen predmet razprav med Vzhodom in Zahodom ter med tradicionalnimi in sodobnimi interpretacijami islama, se je praksa pokrivanja telesa kot običaj pojavila že veliko pred dejansko vzpostavitvijo islama. Praksa pokrivanja žensk naj bi izvirala iz kulture Asirije (današnjega Iraka), Perzije (Irana) in Bizantinskega cesarstva, pojavila pa naj bi se precej pred rojstvom islamske religije v 7. stoletju (Zahedi 2007). Prvi zgodovinski dokazi, ki pričajo o pokrivanju, so asirska pravna besedila iz 13. stoletja pr. n. št. Meščanke višjega razreda so tančico nosile kot znak prestiža in kot privilegirano sredstvo za zaščito pred »nečistim« pogledom običajnih ljudi. Nošenje tančice je bilo prepovedano ženskam nižjega razreda in prostitutkam. Kulturna praksa uporabljanja kosa tkanine kot naglavnega pokrivala za moške (turban) in ženske (tančica) je prišla v navado na Bližnjem vzhodu ter v predelih Afrike in Južne Azije. S prihodom islama so te prakse pokrivanja, ki so se razlikovale glede na specifične lokacije in kontekste, pridobile religiozne konotacije (prav tam).

Nošenje tančice se je najprej uveljavilo med elito. Sam koncept pokrivanja glave tako v židovstvu/judovstvu, islamu kot tudi krščanstvu je povezan predvsem s spodobnostjo in skromnostjo. V srednjem veku si je večina evropskih in bizantinskih poročenih žensk pokrivala lase s številnimi različicami naglavnih in naprsnih rut ter naglavnih šalov. Podobe zahodnoevropskih meščank pričajo o tem, da so si pokrivale vse telo, razen obraza in dlani. Običajno so si z draperijo zakrile vrat, spodnji del vratu pa z naprsno ruto (Hume 2013). Takšna oprava je pozneje vplivala na oblikovanje vizualne podobe nun, katerih oblačilni slog velja za najkonservativnejši v krščanstvu. Tudi Devica Marija je na tradicionalnih upodobitvah prikazana pokrita. Oblačenje žensk v srednjeveški Evropi je bilo dosti bolj podobno oblačilni kulturi muslimank, kot pa je to prepoznano v sedanjem času (prav tam).

V 19. stoletju je v Evropi in Ameriki postalo popularno eksperimentiranje z različnimi oblikami naglavnih pokrival in drugimi kosi oblačil, ki so spominjali na orientalski (turški) slog oblačenja (Kaiser 2012: 95). Ameriške feministke, kot na primer Amelia Bloomer, so odvrgle korzet in nabrano krilo ter za reformirano obleko predstavile aladinke - široke, v gležnju zožene hlače. Navdušenje nad orientalizmom se je kazalo tako v baletu kot modnem oblikovanju. Ruski balet Arabske noči, za katerega je kostume oblikoval sloviti kostumograf Leon Bakst, je navdušil francoskega kreatorja Poireta, ki je orientalsko estetiko ponesel do modno ozaveščenih Parižank. Popularnost tančice in turbana so v dvajsetih in tridesetih letih 20. stoletja nadaljevale hollywoodske filmske zvezde, katerih podoba še dandanes navdihuje številne modne oblikovalce po celem svetu (prav tam).

\section{TANČICA IN ISLAM}

Nošenje tančice ima dolgo in zapleteno zgodovino. Številne muslimanke s tančico potrjujejo svojo kulturno identiteto in afirmirajo težnje po osvoboditvi izpod kolonialne zapuščine. Z zakrivanjem glave in telesa ne izražajo le nasprotovanja vplivom Zahoda, pač pa tudi nasprotovanje pogledom moških v javnosti. Tančica za te ženske pomeni intimno povezavo med lastnim telesom in skupnostjo (El Guindi 1999). V islamu naj bi bilo pokrivanje las in glave nadaljevanje predislamskih praks. Predislamski nomadski Arabci so svoje ženske 
začeli pokrivati, da bi jih zaščitili pred pogledi, napadi, ugrabitvami in posilstvi tujcev oziroma potencialnih sovražnikov. Srednji vek je prinesel številna pravila, ki so ženskam odvzela določene pravice, jim zapovedala pokrivanje in jim omejila aktivnosti zunaj doma. Pokrivanje kot statusni simbol je bilo med vladajočim razredom ter urbano elito splošno sprejeto šele z vladavino Safavidov (1501-1722) in v času Otomanskega imperija (13571924), ki se je raztezal na območju današnjega Bližnjega vzhoda in Severne Afrike. Zanimivo je, da so tudi muslimani začeli pokrivanje žensk upravičevati $\mathrm{v}$ imenu islama šele potem, ko so ga zahodni kolonialisti označili za prominentni simbol muslimanskih družb (Hoodfar 1997: 251).

Raznolikost, značilna za zgodovinsko dediščino posameznih islamskih dežel, od Turčije, Maroka, Irana, Pakistana, Afganistana do Indonezije itd., ki se razlikujejo tudi med mestnim, podeželskim, sedentarnim in nomadskim prebivalstvom, odraža heterogenost islamskega sveta tudi glede oblačenja, saj ni enotnega oblačilnega kodeksa. V ženski muslimanski noši obstajajo trije različni tipi naglavnih pokrival: »hidžab «, "al-amira« in »šajla«. Hidžab, najbolj razširjeno naglavno pokrivalo muslimank, je ruta, ki pokriva lase in vrat, obraz pa pušča odkrit. Tudi »al-amira" pokriva lase in vrat, sestavljena pa je iz dveh delov: cevastega traku, ki pokriva lase in čelo, ter širšega traku, ki sega na ramena. V zalivskih državah je pogosta »šajla«, ki je najbolj podobna zahodnemu šalu in se spenja podobno kot »hidžab « ali pa se lahkotno ovije okoli glave in enkrat ali večkrat okoli ramen. Pod njo se vedno nosi oprijeta čepica, ki preprečuje, da bi lasje padali na obraz. V Savdski Arabiji poleg naglavnega pokrivala ženske nosijo še »nikab«, ki je namenjen pokrivanju obraza. "Nikab " prekriva večji del obraza in pušča odkrite le oči. V primeru popolnega "nikaba« je tudi predel okoli oči zastrt s prosojno tančico, običajno pa se zraven nosijo tudi rokavice (Harcet 2007: 66).

V kombinaciji z naglavnim pokrivalom se po navadi nosi obleka, imenovana "abaja« ali »džilbab«. »Abaja« je dolga ohlapna obleka, ki jo nosijo predvsem Savdijke in ženske v zalivskih državah. "Džilbab« je soroden "abaji«, vendar je v zgornjem delu bolj podoben suknjiču, ki ga krasi ovratnik. »Džilbab«, ki ga uporabljajo v Jordaniji, Siriji, Palestini, Libiji in Alžiriji, se lahko nosi s hlačami ali z dolgim krilom nad majico ali bluzo. Od ogrinjal oziroma plaščev obstajajo »kimar«, »čador« in »burka«. »Kimar« je dolg, pelerini podoben plašč, ki pokriva lase, vrat in ramena. Navadno pada čez boke, lahko pa sega tudi pod kolena. »Čador«, ki ga nosijo predvsem porevolucijske Iranke, je podoben »kimarju«, le da je daljši in navadno sega do gležnjev. Najbolj ekstremno oblačilo islamskega sveta, ki je značilno predvsem za Afganistan, pa je »burka«, pri kateri gosta tkanina popolnoma pokriva celotno telo, vključno z obrazom, le v predelu oči je gosta mreža, ki omogoča le majhno vidljivost (prav tam 2007: 66).

Različne interpretacije islamskih svetih predpisov ter različni političnozgodovinski vidiki v posameznih islamskih državah kažejo pri ženskah na bistvene razlike glede oblik, materialov in barv oblačil. Tradicija zakrivanja izvira iz globoko zakoreninjene miselnosti patriarhalne islamske kulture, da je ženska skušnjavka, ki jo je treba zakriti. Čeprav nošnja "nikaba«, "čadorja« ali »burke« oziroma pokrivanje žensk od glave do peta v Koranu ni eksplicitno predpisana, je tančica postala sestavni del identitete mnogih muslimank. V nekaterih kulturnih okoljih šele popolni »nikab«, »čador» ali »burka« ženskam omogočajo prisotnost v dominantni moški družbi. Prav nošnja teh oblačil je prvi korak k vključevanju žensk v javno življenje (Hosseini 1996: 96). V Koranu, ki tako za ženske kot moške predpisuje spodobno oblačenje, s katerim naj bi izražali svojo vero in moralno držo, se predpisi 
o oblačenju omenjajo le na treh mestih. V poglavju Zavezniki je odlomek, ki predpisuje dostojno oblačenje žensk: »O, glasnik vere! Reci svojim ženam, svojim hčeram in ženam vernikov, naj se dostojno oblačijo. Tako bodo lahko prepoznane, nihče pa jih ne bo nadlegoval. Gospod pa odpušča in je milosten« (Koran 30: 59). V odlomku Svetloba, ki govori o sredstvih za preprečevanje nečistovanja, je zapisano: »Reci vernikom, naj hodijo s spuščenim pogledom in naj pazijo na svoje sramne dele. Tako je bolje, saj Gospod resnično ve, kaj delajo« (Koran 24: 30).

Iz zapisanega lahko razberemo, da tudi za moške velja enako kot za ženske, da se ne smejo spogledovati s tujci in da ne smejo dovoliti, da bi se videli določeni deli telesa. Temu določilu sledi navodilo za ženske: „Vernicam reči, naj hodijo s spuščenim pogledom in naj pazijo na svoje sramne dele ... Tančice naj imajo čez prsi, svojega okrasja pa naj ne kažejo naokrog! ... Naj ne udarjajo s stopali, da bi se slišal žvenket nakita, ki je pod obleko « (Koran 24: 31). V poglavju Svetloba je tudi določilo o odevanju starejših žensk: »Za ostarele ženske, ki si ne želijo več poroke, ni greh, če odložijo svoja ogrinjala, vendar ne smejo razkrivati delov telesa z okrasjem « (Koran: 24: 60). Čeprav je obdobje na prelomu 19. v 20. stoletje pri pokrivanju $^{5}$ prineslo spremembe, sta se nošenje tančice in zapriseženost skromnejši obleki, $\mathrm{v}$ smislu nasprotovanja zahodnemu svetu in zahodnim političnim vmešavanjem v nacionalne režime, v drugi polovici 20. stoletja ponovno začela uveljavljati. Tančico kot simbol ponovne vzpostavitve narodne identitete in pokazatelja zavračanja vrednot in stilov, ki so ali se zdijo zahodnjaški, danes še zlasti popularizirajo Indonezija, Filipini, Pakistan, Iran, Afganistan idr. (Tarlo, Moors 2007).

\section{Islamski feminizem, kritika oblačilnih praks zakrivanja in sodobnost}

Ob koncu 19. stoletja so islamski intelektualci in reformatorji, da bi muslimanske države postavili ob bok sodobni zahodni civilizaciji, začeli oznanjati nove ideje o liberalizaciji žensk. Te ideje so vključevale spremembe statusa žensk in tradicionalnih običajev, kot so pokrivanje žensk, izključitev iz javnega življenja in neenakost v izobraževanju. Leila Ahmed (1992) ta diskurz imenuje »kolonialni feminizem«. Burne razprave, ki so se začele v Egiptu, je spodbudila knjiga muslimanskega sodnika Qasim Amina Osvoboditev ženske (ang. The Liberation of Women, 1899), ki naslavlja potrebo po splošni kulturni in družbeni transformaciji egipčanske družbe, pri čemer je odprava pokrivanja žensk med ključnimi spremembami.

Za začetnici ženskih gibanj v islamskem svetu veljata Egipčanka Huda Shaarawi (1879-1947) in Libanonka Nazirah Zayn al-Din (1908-1975), ki sta med prvimi javno sneli pokrivala. Prvo uradno islamsko feministično gibanje Feministična zveza Egipta, ki ga je leta 1923 ustanovila Huda Shaarawi, si je prizadevalo za pridobitev volilne pravice žensk, možnost izobraževanja in spremembe šeriatskega prava, kar so bila primarna področja delovanja prvih aktivističnih prizadevanj v islamskih državah « (Mir Hosseini 1999: 7, 96). Kot koncept in osrednji termin, ki označuje delovanje žensk islamske veroizpovedi za izboljšanje njihovega položaja na globalni ravni, se je v devetdesetih letih 20. stoletja. »islamski femizem« začel uporabljati v vedno večjem številu literarnih del o ženskah in islamu. Kot »feministični diskurz in praksa, artikulirana znotraj islamske paradigme, izhaja iz Korana 
in se nanj sklicuje kot na temelj pravičnosti in zavzemanja za eksistenčne pravice tako žensk kot moških« (Badran 2009: 242). Za proizvajalce in uporabnike islamskega feminističnega diskurza lahko imenujemo tiste, ki islamsko feministično etiketo oziroma identiteto sprejemajo ali pa je ne. Mednje spadajo tako verni muslimani, sekularni muslimani (katerih pripadnost islamski veroizpovedi je manj očitna za javnost) kot tudi nemuslimani. Pomembno je tudi, da historiciramo in kontekstualiziramo uporabo pojmov »religiozen« in »sekularen«, saj se njuni pomeni razlikujejo glede na čas in prostor (prav tam: 244).

Islamski feminizem je pomemben, ker naslavlja islamski patriarhalni establišment $\mathrm{v}$ njegovem lastnem jeziku. Predstavlja obliko upora tako proti patriarhalnemu islamu kot tudi zahodnemu (kulturnemu) imperializmu. Irshad Manji, sicer globoko verna muslimanka in javno izpovedana homoseksualno usmerjena oseba, analitična kritičarka islama in islamskega fundamentalizma, goreča borka za žensko enakopravnost in prenovo islama, v svoji knjigi v obliki odprtega pisma Kaj je danes narobe $z$ islamom (2003) kritizira plemensko islamsko ureditev, samovoljno tolmačenje Korana in sodobno suženjstvo:

Milijoni muslimanskih žena zunaj Arabije, vključno z Zahodom, se zastirajo. To sprejemajo kot dejanje verske poslušnosti. V resnici pa je to prej dejanje kulturne kapitulacije [...] to, da si zakrivam obraz, ker se to od mene pričakuje, ni nič drugega kot zmaga blagovne znamke puščavskih Arabcev, katerih slog oblačenja je postal najzanesljivejši simbol, kako se je kot muslimanka treba zapakirati. Posnemati puščavska ljudstva v oblačenju, jeziku ali molitvi ne pomeni nujno slediti univerzalnemu Bogu. Toda iz mitov, ki že stoletja propagirajo islam, tega ne morete vedeti. Ti miti so spreobrnili nearabske muslimane v stranke svojih arabskih gospodarjev, ki morajo kupiti to, kar jim prodajajo v imenu islamske »razsvetljenosti«. (Manji 2008: 189)

Tudi Fatima Mernissi opozarja, da je razumevanje oblačil kot »sredstva za zaščito« sporno, saj predvideva, da je žensko telo izziv za moške, ki jim je dovoljeno agresivno spolno vedenje do nezaščitenih žensk. Ženska, ki ni primerno oblečena in ni v spremstvu moškega, je namreč grozeča nevarnost, ki ji je treba omejiti svobodo, jo zastreti, zapreti. Tako imenovana skrb za zaščito žensk, ki jo predpisuje islamska vera, številnim muslimankam hkrati pomeni omejevanje njihovih pravic (Mernissi 1992: 180-183). Razkrivanje in svobodna izbira o nošenju »hidžaba" mnogim muslimanskim ženskim aktivistkam in islamskim feministkam pomeni eno ključnih orodij boja proti patriarhalni islamski družbi. (Ne)nošenje tančice pa nima le politične konotacije; pokrivanje ali razkrivanje se odražata kot intimna stiska ženske, ki nima svobodne izbire. Ko je leta 1936 šah Reza Khan Pahlavi prepovedal nošenje ženskih pokrival v javnih prostorih, si nekatere ženske mesece niso upale iz hiše, ker so se počutile osramočene in ponižane, medtem ko je bila poznejša generacija žensk ogorčena nad ukrepi fundamentalistične vlade ajatole Ruholaha Homeinija, ki je prišla na oblast po islamski revoluciji leta 1979 in ženskam zaukazala ustrezno pokrivanje.

Pri tem niti ne gre toliko za samo tančico kot za vprašanje svobodne izbire. Moja babica tri mesece ni zapustila domače hiše, ko so jo silili, naj se odkrije. Jaz bom pri svojem zavračanju prav tako odločna. Le da takrat še nisem vedela, da bom zelo kmalu pred edino izbiro: ali tančica ali pa zapor, palica in morda smrt, če se ne pokorim. (Nafisi 2004: 157)

Podobno pričevanje o ustrahovanju žensk in predpisovanju strogih oblačilnih standardov zanje dokumentira tudi iranska pisateljica Marjane Satrapi (2008). Satrapi v romanu 
s humorno obarvanimi stripovskimi sličicami prikaže svoje otroštvo v revolucionarnem Iranu s konca sedemdesetih let 20. stoletja, nato pa svoje najstništvo na sekulariziranem Dunaju. V njej se prepletajo bolečine in strahovi, hrepeneče upanje po reševanju sveta, upor proti nesmiselnemu omejevanju osebne svobode ter iskanje lastne identitete, ki ga doživlja kot najstnica. Veščina njene narativnosti in sposobnosti prikaza različnih čustev ter vpogledov v družbeno življenje z veliko mero prodorne inteligence in humorja razpršuje mite ter potrjuje strahove, ki jih je preganjalski politični režim včrtal v oziroma na telo posameznika in naroda.

Nafisi in Satrapi z avtobiografskima pripovedma, vsaka na svoj način, razkrivata kompleksno prepletanje osebnega in političnega, individualnega in družbenega. S tem »muslimansko« žensko oblačilo predvidita kot dinamičen proces, ki se pogaja o meji med omenjenimi področji. Njuni intimni zgodbi utelešata predstavo obleke kot posrednika pogajanj med svobodo in kontrolo, estetiko in politiko. Obe zgodbi in številne druge, ki se nanašajo na subjektivno percepcijo oblačilnih praks žensk islamske veroizpovedi, izražajo potrebo po tem, da vsaka ženska svobodno izbira svojo vizualno podobo. Svobodna odločitev glede oblačenja je le del obširnejših prizadevanj za enakopravnost žensk v muslimanski patriarhalni družbi, za katero si prizadevajo islamska feministična in druga ženska aktivistična gibanja ter posameznice po celem svetu. Diskriminacija in rasizem, ki ju pogosto doživljajo pokrite muslimanke na Zahodu, sta namreč prav tako zatirajoča, kot je ponižujoča splošno uveljavljena percepcija mnogih zahodnih feministk, ki kolonialistične podobe muslimank in muslimanskih družb uporabljajo kot orodje v boja proti seksizmu. Hooma Hoodfar, profesorica Oddelka za sociologijo in antropologijo na Univerzi Concordia v Montrealu v Kanadi in Iranka, v enem svojih člankov zapiše bridke besede svoje sonarodnjakinje, izrečene na eni od feminističnih konferenc: »Trpele smo v imenu napredka, potem v imenu revolucije, nato $\mathrm{v}$ imenu islama, pozneje emigracijo in rasizem, zdaj pa moramo trpeti še $\mathrm{v}$ imenu feminizma« (Hoodfar 1997: 267).

Čeprav so številne muslimanke aktivne v javnosti in vidno sooblikujejo islamsko družbo, neenakosti med spoloma $\mathrm{v}$ dostopu do izobraževanja in zaposlovanja še vedno obstajajo in ovirajo njihovo svobodno izražanje, obnašanje in oblačenje. Številne islamske feministke verjamejo, da mora osvoboditev žensk izvirati iz religije, pri čemer se zavzemajo za reinterpretacijo Korana ter spremembo šeriatskega prava, saj bodo muslimanke le tako lahko dosegle svojo emancipacijo. Čeprav se prizadevanja islamskega feminizma za enakopravnost tako ali drugače dotikajo islama, pa v središču ni vera, temveč ženske.

\section{PERCEPCIJA ZAHODA}

Verska obleka je že po sami definiciji vidni označevalec razlike. Prinaša sporočilo o določenemu naboru ideoloških ali verskih načel in praks. Specifične, religiozno obarvane oblačilne prakse določeno versko skupnost ločijo od drugih verskih skupnosti, hkrati pa je tudi v skupnosti treba razlikovati hierarhijo, strukture oblasti, razlike med spoloma, ideje o skromnosti, posamezne vloge, običaje, identitete, prepričanja in ideologije« (Hume 2013: 1). Zahodni svet na splošno razume tančico kot zatiralno orodje konservativnega in patriarhalnega islama. $\mathrm{Z}$ natančnejšim opazovanjem življenjskega horizonta postane zgodba kompleksnejša. 
Ruta je simbol islama, vendar nič manj tudi simbol upora samozavestnih in razsvetljenih žensk, ki so se opredelile za islam tudi zato, da bi se branile pred diskriminacijo, zahtevami po asimilaciji in da bi si izborile pravico do samostojne, neodvisne identitete, ki se sme razlikovati od vsiljenih identitet, ki jih predpisuje večinska kultura. (Kalčič 2007: 271)

Nošenje pokrival v nemuslimanskih državah je za javnost pogosto problem, saj ga zahodna družba v glavnem razume kot simbol zavračanja asimilacije, grožnje islamskega fundamentalizma in navsezadnje terorizma. Zaradi omenjenih interpretacij muslimanke, ki živijo na Zahodu in so pokrite oziroma želijo biti pokrite, pogosto postanejo žrtve diskriminacije in obtožb. Ne le, da na primer večina evropskih držav prepoveduje popolno pokrivanje las in obraza v javnih ustanovah, mnoge ženske, ki se ne želijo (ali ne smejo) odreči pokrivalu, ne dobijo zaposlitve. Seveda je težko določiti meje, kdaj gre za svobodno odločitev in kdaj za prilagajanje družinskim ter družbenim normam.

Za številne imigrantke islamske veroizpovedi Zahod, vsaj teoretično, predstavlja svobodo »biti muslimanka" po lastni izbiri. Toda ali Zahod dejansko izpolnjuje njihova pričakovanja, da bodo svobodne tudi pri izbiri oblačenja? Gotovo ne v vseh primerih. In skoraj $\mathrm{v}$ vseh državah, kjer se muslimanske manjšine povečujejo in postajajo vidnejše, se zaradi tančice pojavljajo vse razvidnejši primeri diskriminacije (Haddad 2002: xiv). V knjigi Veil: Mirror of Identity (2009) sociolog Christian Joppke ponudi precej provokativno razpravo o mnogoterih pomenih tančice $\mathrm{v}$ povezavi $\mathrm{z}$ vzponom islama $\mathrm{v}$ svetovni perspektivi, muslimansko integracijo in s trenutnim evropskim zavračanjem večkulturnosti. Zanj je tančica ogledalo prepleta nacionalnih in liberalnih identitet, kar pa postavi tančico za paradoks sam po sebi: tako kot je tančica $\mathrm{v}$ zahodnem pogledu predstavljena kot žalitev liberalnih vrednot, je neliberalno zatiranje tančice (Joppke 2009). »Islamsko naglavno pokrivalo deluje kot ogledalo identitete, ki sili Evropejce, da vidijo, kdo so in da ponovno razmislijo, kakšne javne institucije in družbe želijo imeti« (prav tam: 2).

Islamska tradicija je v oblačenju kot okraševanju teles diametralno nasprotna zahodni oblačilni kulturi. Sodobna »Zahodnjakinja« svojo ženstvenost kaže s pozornostjo, ki jo namenja svojemu telesu in oblekam: "muslimanka« naj bi svojo ženstvenost pokrila in jo skrila za tančico. Lahko bi rekli, da "muslimanska ženska" predstavlja »sveto telo", »Zahodna ženska« pa »estetsko telo«. Prizadevanje za skromno in nevpadljivo podobo verne muslimanke danes ni najbolj usklajena s porastom dobičkonosne islamske modne industrije, ki je postala simbol novega islamskega potrošništva. Za podrobnejšo analizo sodobne islamske mode kot transnacionalnega in populariziranega pojava pa se je treba najprej poučiti o zgodovini 20. stoletja, ki je v islamskih državah na vseh področjih prinesla velike spremembe.

\section{SODOBNA ISLAMSKA MODA IN MODNA INDUSTRIJA}

Danes muslimani na Zahodu svojo kulturno identiteto in vero veliko bolj izražajo z obleko, bodisi pri nošenju tradicionalne dolge črne obleke bodisi novih modnih stilih, ki vključujejo pisane naglavne rute. Multikulturnost in hibridni "hidžabi« so del prenove oziroma 'remodeliranja' (ang. refashioning) islama na Zahodu. Sodobne muslimanske ženske različne stile oblačenja izbirajo iz širokega kulturnega repertoarja, ki definirajo načine, kako biti »musliman v Londonu« (Tarlo 2010). 
$\mathrm{V}$ tem kontekstu se pojavljajo nove klasifikacije in kontekstualizacije muslimanske obleke, od »neislamske« in slogov, ki se povezujejo z Bližnjim vzhodom in Afriko, do avtentično »islamskih«. Vsi ti raznoliki slogi soobstajajo s še bolj eklektičnimi kombinacijami »islamske mode«, oblikovanimi posebej za potrebe zahodnega trga. (Tarlo 2010: 7)

Od začetka 20. stoletja je med prebivalstvom centralnih držav Bližnjega vzhoda priljubljeno oblačenje $\mathrm{v}$ zahodne modne oblačilne sloge, kar je sprva povzročilo opuščanje nošenja tančice čez obraz, nato pa še naglavne rute. Po političnih spremembah ${ }^{6} \mathrm{v}$ sedemdesetih letih 20. stoletja so številne ženske v Turčiji začele nositi nov slog "pokrite« obleke, ki se je imenovala »nova tančica» (Tarlo, Moors 2007: 339).

Ker je dejansko šlo za nov stil obleke, razvidno drugačen od predhodnih pokritih oblačilnih slogov revnejših urbanih in podeželskih žensk, so bile te prakse prepoznane kot nove. Ženske, od katerih se je pričakovalo, da bodo nosile zahodno modo, so zavestno izbrale vrnitev k islamskemu slogu pokrite obleke. Nekatere ženske, ki so začele nositi ta stil obleke, so bile del nabožnega gibanja, ki se je pojavilo kot odziv na vse večjo sekularizacijo vsakdanjega življenja. Za druge je bilo nošenje "nove tančice« način za izražanje svoje naklonjenosti kulturni politiki islamističnih gibanj, ki niso bilo le oblika upora proti zahodni nadvladi, pač pa tudi kritičen pogled na lokalne avtoritarne režime, ki so v prakse oblačenja vnašali zahodne identitete in naraščajočo materialistično kulturo. Kot del teh gibanj se je razvil uniformiran in nevpadljiv slog pokrite obleke. Z novim pokrivanjem so mnogi pripadniki omenjenih gibanj želeli za vedno opraviti z modo in še zlasti z razlikami med bogatimi in revnimi (prav tam).

$\mathrm{V}$ poznih osemdesetih in devetdesetih letih 20. stoletja je trend islamizma sam po sebi postal bolj heterogen. Trend se je deloma transformiral iz antipotrošniškega radikalnega gibanja k bolj individualiziranemu reformističnemu gibanju $\mathrm{z}$ identitetami, ki so se vedno bolj izražale s potrošništvom. Pojav islamske potrošniške kulture je vodil v večjo heterogenost islamskih slogov oblačenja in $\mathrm{v}$ naraščajočo modno ozaveščenost med mladimi muslimankami višjega razreda. Estetske presoje, izbran okus ter kulturni in finančni kapital so pokazatelj procesov, ko so islamistične ženske začele nositi islamsko obleko in jo spremenile v modo (prav tam: 340 ).

Danes lahko tako v »zahodnem« kakor tudi »muslimanskem» okolju Bližnjega vzhoda in Jugozahodne Azije zasledimo raznolike, raznobarvne in nenehno spreminjajoče se sloge pokrite islamske mode. Nova vzhajajoča in dobičkonosna islamska modna industrija, ki se nanaša na proizvodnjo, distribucijo, oglaševanje in prodajo, je del potrošniškega življenjskega stila nove urbane muslimanske populacije. Pogosto glamurozni modni oglasi v ženskih revijah nikakor ne poosebljajo skromne islamske obleke, kot jo predpisuje Koran. Privabljajo pogled, zapeljujejo in predvsem ne ustrezajo islamskim principom. In vendar prav oglaševanje igra ključno vlogo v ustvarjanju profitabilne tržne niše, kot je današnja islamska modna industrija. Izvor njene kontroverznosti se skriva prav v prepletu dveh navidezno neujemajočih se sistemov: mode in islama. Pokrita moda in njeni dizajni so v zadnjem desetletju po vsem svetu tudi odziv na post-9/11, geopolitično okolje in porast

6 Eden pomembnejših dejavnikov, ki je odprl pot svobodnemu ženskemu gibanju, je bil prav državni udar leta 1980; v takratnih političnih okoliščinah je namreč nastal vakuum, ki so ga izkoristile predvsem ženske. Sodobni feminizem oziroma žensko gibanje v Turčiji in drugod sta se poleg boja za enakost žensk začela ukvarjati tudi z bojem za pravico do drugačnosti žensk, kar je postalo razvidno zlasti z razvojem sodobnih kritik zahodnega »belega« feminizma (Frank 2012: 50, 51). 
antiislamizma. Svetlejša in bolj všečna pokrita moda je postala pomemben predmet razlikovanja med »dobrimi« in »slabimi« muslimani.

Ko so mediji stigmatizirane podobe muslimank $\mathrm{z}$ ruto in muslimanov $\mathrm{z}$ brado označili za simbole islamistične militantnosti, je postalo še pomembnejše portretirati ugajajoč, eleganten in moderen videz. Črna in temnejša »tesettür « ${ }^{7}$ oblačila ter ogromni šali so postali manj priljubljeni. Novi moderni slog pokrivanja se je bliskovito razširil na večje skupine ljudi, ki pred nepokrito javnostjo niso želeli izgledati odbijajoče, oz. da bi jih ta stereotipno označila za grde, nazadnjaške in strah vzbujajoče. (Sandıkçı, Ger 2007)

»Moderne muslimanke« so postale eden najočitnejših subjektov diskurza o islamizmu, vlogi spolov in potrošništvu. S prilagajanjem in soustvarjanjem lastne kompleksne vloge, ki niha med tem, kako biti "muslimanka" in hkrati "moderna ženska», preverjajo nove islamske identitete ter oznanjajo spreminjajoče se meje med islamsko etiko in imperativi neoliberalnega kapitalizma. $\mathrm{V}$ današnjih urbanih okoljih transnacionalna muslimanska obleka po vsem svetu priča o tesni povezavi med "islamsko" in "zahodno" modo in se izraža tako v njenih proizvajalcih kot potrošnikih. Ne gre toliko za "nezahodni svetovni modni sistem«, pač pa bolj za globalni islamski okvir, v katerem oblikovalci, podjetniki, potrošniki, uporabniki interneta in medijski komentatorji širijo ponudbo modnih možnosti, z razvojem značilnih islamskih stilov, s pestrim naborom slogov, spreminjanjem in kombiniranjem elementov prevladujoče mode pa tako soustvarjajo nove »islamsko občutljive« obleke (Tarlo 2007: 224, 225).

\section{ZAKLJUČEK}

Čeprav številke muslimanke poudarjajo predvsem verski pomen tančice, ki naj bi poudarjala njihovo pripadnost islamski kulturi, je dejstvo, da so prav njihova oblačila postala simbol in politična poteza. Ko izbira oblačenja ni več svobodna domneva in kjer ni svobodne izbire oblačenja, obleka postane orodje moči, ki ga upravljajo in nadzirajo verske oziroma politične institucije. Vendar tudi prisilna zavrnitev globoko zakoreninjene tradicije ni preprosta in je hkrati druga oblika diskriminacije. Nošenje pokrival v javnosti seveda ne ponuja enostavnih odgovorov, zato o pomenu in vlogi tančice ne moremo razpravljati, ne da bi razumeli pomen in vlogo patriarhalne muslimanske zapuščine ter njene verske prakse. Ko razpravljamo o oblačilni kulturi muslimank, se moramo v imenu strpnosti do današnje družbe zavedati svojega "zahodnega" pogleda na islamski svet, hkrati pa ne smemo pozabiti na omejevanje verske svobode in svobode izražanja. Sodba o pokrivanju muslimank je tako večplasten pojem, ki vlogo tančice kot čaščene ali preklete ikone islama bolj ali manj pušča odprto za subjektivne sodbe, bodisi v smislu odobravanja bodisi zavračanja.

Stalno spreminjajočo se družbeno vlogo muslimanske tančice razkriva tudi pojav nove islamske modne industrije, ki je v zadnjih dveh desetletjih kot transnacionalni pojav razvidno zaznamovala globalno družbo. Muslimanske oblačilne prakse danes vstopajo $\mathrm{v}$ novejše poglavje svoje zgodovine, ki ga $\mathrm{z}$ novo islamsko modo in mednarodno modno industrijo pišejo nove oblike islamske etike, potrošništva in neoliberalnega kapitalizma.

»Tesettür« je splošni izraz za islamski način oblačenja v današnji Turčiji. 
Sodobna islamska modna industrija tako v očeh javnosti pooseblja simbol islama kot političnega sistema, spodbija pa koncept pokrite ženske kot nečesa zastrašujočega, saj žensko identiteto utemeljuje na pojmih lepote, privlačnosti in seksualnosti. Moderna muslimanska ženska s svojim ozaveščenim modnim, ženstvenim in še vedno ikoničnim videzom ustvarja kontroverzne polemike o razumevanju islama $v$ današnjem globalnem svetu. Eden razvidnejših kulturnih vidikov migracij muslimanskega prebivalstva v države Evrope in Amerike se nanaša tudi na migracijo in transformacijo pomenov oblačilnih praks. Tradicionalna, $\mathrm{v}$ primeru pričujoče študije muslimanska obleka igra pomembno vlogo pri oblikovanju novih identitet ter odseva zapleteno povezavo med pomenom identitete in subjektivnosti. Muslimanska obleka v izrazito nemuslimanskih državah priseljenim muslimanskim ženskam pogosto pomeni ustvarjanje hibridnih form nove muslimanske obleke. Tradicionalna oblačila se ne prilegajo le trendom glede barv in materialov, pač pa se pojavljajo v kombinaciji z džinsom, ki sicer pooseblja tipično zahodnjaški slog.

Te hibridne oblačilne prakse odsevajo kulturne spremembe, katerim smo priča v zadnjih dveh desetletjih in so povezane ne le z migracijami v materialnem in kulturnem smislu, pač pa tudi z novim konceptom medkulturne komunikacije in novimi subjektivnimi usmeritvami v percepciji današnje družbe. Oblikovanje nove muslimanske mode je povezano z oblikovanjem hibridnih kulturnih form oblačil, ki se estetsko in materialno napajajo v vzhodni (muslimanski) in zahodni kulturi ter so odvisne od priložnosti in konteksta nošenja v določenem okolju. Če sta se še pred desetletjem vizualni podobi v Londonu živeče zakrite muslimanke in v Jakarti živeče zakrite muslimanke razlikovali, danes te razlike ni več. Tančica kot del današnje oblačilne prakse muslimank ni le poosebljena manifestacija islamske vere, vpete v vizualno podobo muslimanske ženske, pač pa je večplasten pojem in koncept, globoko integriran v politične, družbene, osebne in navsezadnje vizualne interpretacije. Njena ikonična podoba ne odseva le religiozne identitete ženske, ki jo nosi; njena heterogenost razkriva mnogo kompleksnejšo in intimnejšo sfero, ki se nanaša tako na regionalne in družbene norme kot na moralne in estetske principe. Tančica je simbol in metafora, ki artikulira dejstvo, da religija, moda in politika niso nezdružljive, ampak so intimno povezane in udejanjene $\mathrm{z}$ obleko.

\section{LITERATURA}

Appadurai, Arjun (1990). Disjuncture and Difference in the Global Cultural Economy. Public Culture 2(2), http://www.arjunappadurai.org/articles/Appadurai_Disjuncture_and_Difference_in_the_Global_Cultural_Economy.pdf (11.6. 2017).

Appadurai, Arjun (1996). Modernity at Large. Minneapolis: University of Minnesota Press. Ahmed, Leila (1992). Women and Gender in Islam: Historical Roots of a Modern Debate. New Haven, London: Yale University Press.

Badran, Margot (2009). Feminism in Islam: Secular and Religious Convergences. Oxford: Oneworld, http://humanities.wisc.edu/assets/misc/What_is_Islamic_Feminism.pdf (29. 7. 2017).

El Guindi, Fadwa (1999). Veil: Modesty, Privacy and Resistance. Oxford, New York: Berg. Frank, Ana (2014). Feminizem in islam: Turške ženske med Orientom in Zahodom. Ljubljana: Mirovni inštitut. 
Gökarıksel, Banu, Secor, Anna J. (2009): New Transnational Geographies of Islamism, Capitalism and Subjectivity: The Veiling-Fashion Industry in Turkey. Area 41/1, 6-18.

Haddad Yazbeck, Yvonne, Smith, Jane (2002). Muslim Minorities in the West: Visible and Invisible. Walnut Creek, Lanham, New York, Oxford: Altamira Press.

Harcet, Marjana (2007). Alahove neveste: Med podrejenostjo in avtonomijo. Ljubljana: ISH, Fakulteta za podiplomski humanistični študij.

Hoodfar, Homa (1997). The Veil in Their Minds and on Our Heads: The Persistence of Colonial Images of Muslim Women. Politics of Culture in the Shadow of Capital (ur. David Lloyd, Lisa Low). Durham, London: Duke University Press, 248-279.

Hume, Llynne (2013). The Religious Life of Dress: Global Fashion and Faith (Dress, Body, Culture). London, New York: Bloomsbury Academic.

Joppke, Christian (2009). Veil: Mirror of Identity. Cambridge, Malden: Polity Press.

Kaiser, Susan (1999) Identity, Postmodernity and the Global Apparel Marketplace. Meanings of Dress (ur. Mary Lynn Damhorst, Kimberly A. Miller, Susan O. Michelman). New York: Fairchild Publications, 106-114.

Kaiser B., Susan (2012). Fashion and Cultural Studies. London, New York: Bloomsburry Academic.

Kalčić, Špela (2007). Nisem jaz Barbika: Oblačilne prakse, islam in identitetni procesi med Bošnjaki v Sloveniji. Ljubljana: Oddelek za etnologijo in kulturno antropologijo Filozofske fakultete Univerze v Ljubljani.

Koran (2004). Tržič: Učila International.

Manji, Irshad (2008). Kaj je narobe danes z islamom: Poziv k poštenosti in prenovi? Petrovče: Znamenje.

Mernissi, Fatima (1992). The Veil and the Mail Elite. New York: Basic Books Group.

Mir Hosseini, Ziba (1999). Islam and Gender: The Religious Debate in Contemporary Iran. New Jersey: Princeton University Press.

Nafisi, Azar (2004). Prebiranje Lolite v Teheranu. Mengeš: Ciceron.

Repič, Jaka (2009). Metodologija etnografskega raziskovanja migracijskih in transnacionalnih procesov, http://Metodologija_URN-NBN-SI-DOC-SSRFTQ7T.pdf (11. 6. 2017).

Said, Edward (1996). Orientalizem: Zahodnjaški pogledi na Orient. Ljubljana: Studia Humanitas. Sandıkçı, Özlem, Ger, Güliz (2007). Constructing and Representing the Islamic Consumer in Turkey. Fashion Theory 11/2-3.

Satrapi, Marjane (2008). Persepolis: Zgodba o otroštvu. Ljubljana: Društvo za širjenje filmske kulture KINO.

Tarlo, Emma, Moors, Annelies (2007). Muslim Fashions. Fashion Theory: The Journal of Dress, Body \& Culture 11 (ur. Valerie Steele). New York, London: Berg, 133-142.

Tarlo, Ema (2010). Visibly Muslim: Fashion, Politics, Faith. London, New York: Bloomsbury Academic.

Vertovec, Steven (2001). Transnational Challenges to the 'New' Multiculturalism. WPTC - 01-06. Paper presented to the ASA Conference held at the University of Sussex, 30 March-2 April 2001, http://www.transcomm.ox.ac.uk/working\%20papers/WPTC-2K-06\%20Vertovec.pdf (25. 7. 2017).

Zahedi, Ashraf (2007). Contested Meaning of the Veil and Political Ideologies of Iranian Regimes. Journal of Middle East Women's Studies 3/3, https://ic.ucsc.edu/ rlipsc h/ AFRICOM/Zahedi.pdf (11. 6. 2017).

Wolf, Eric R. (1999). Evropa in ljudstva brez zgodovine. Ljubljana: Studia Humanitas. 


\section{SUMMARY}

\section{ISLAM, TRANSNATIONAL DRESS AND IDENTITY: MIGRATION OF IMAGES, TRANSFORMATION OF MEANINGS \\ Mateja KROFL}

Migration and globalisation today critically impact the redefinition of Muslim dress in the modern world and the formation of the cultural identities of women of the Muslim faith in urban environments. The purpose of the article is to present the transnational significance of the veil (in the form of headgear or body covering) and to offer insights into new interpretations of modern Muslim fashion, which reflects the interweaving of various dress practices in new compositions. The formation of new hybrid forms of Muslim dress is therefore manifested both symbolically and materially in both "eastern" and "western" culture. The article, through a concrete analysis of the problematics arising in connection with Islamic dress codes, indicates that the veil today is not just a personalised manifestation of Islamic faith expressed in the visual image of Muslim women, but a multi-layered concept which is deeply integrated into political, social, personal and also visual interpretations. The new transnational Muslim fashion in the light of transculturality opens up new perspectives on the perception of the identities of "modern" Muslim women and bears significant witness to the cultural importance of migrations. 